\title{
Radiopharmaceutical Volume Administered
}

National Cancer Institute

\section{Source}

National Cancer Institute. Radiopharmaceutical Volume Administered. NCI Thesaurus.

Code C69290.

The amount of radiopharmaceutical given to a subject. 